\title{
The regulation of NLRP3 inflammerch Paper The regulation of NLRP3 inflammasome expression during the development of cardiac contractile dysfunction in chronic kidney disease
}

\author{
Li-Han Chin ${ }^{1}$, Yu-Juei Hsu ${ }^{2,3}$, Shih-Che Hsu ${ }^{3}$, Yen-Hui Chen ${ }^{4}$, Yung-Lung Chang ${ }^{3}$, \\ Shih-Ming Huang ${ }^{3}$, Chien-Sung Tsai ${ }^{1,5}$ and Chih-Yuan Lin ${ }^{1}$ \\ ${ }^{1}$ Department of Surgery, Tri-Service General Hospital, National Defense Medical Center, Taipei, Taiwan \\ ${ }^{2}$ Department of Medicine, Tri-Service General Hospital, National Defense Medical Center, Taipei, Taiwan \\ ${ }^{3}$ Department of Biochemistry, National Defense Medical Center, Taipei, Taiwan \\ ${ }^{4}$ Institute of Biomedical Sciences, Academia Sinica, Taipei, Taiwan \\ ${ }^{5}$ Superintendent's Office, Taoyuan Armed Forces General Hospital, Taoyuan, Taiwan \\ Correspondence to: Chih-Yuan Lin, email: linrock@ms26.hinet.net \\ Keywords: cardiac contractile dysfunction; chronic kidney disease; uremic cardiomyopathy; NLRP3 inflammasome; apoptosis \\ Received: August 18, $2017 \quad$ Accepted: November 09, $2017 \quad$ Published: December 06, 2017 \\ Copyright: Chin et al. This is an open-access article distributed under the terms of the Creative Commons Attribution License 3.0 \\ (CC BY 3.0), which permits unrestricted use, distribution, and reproduction in any medium, provided the original author and source \\ are credited.
}

\section{ABSTRACT}

Chronic inflammation plays a crucial role in the long-term complications in patients with chronic kidney disease (CKD). This study aimed to assess the role of NLR pyrin domain-containing protein (NLRP3) inflammasome in cardiac contractile dysfunctions in CKD. The cardiac contractile function was evaluated and the expression of NLRP3 inflammasome and related cytokines in the heart was assessed in a murine sham-operated and 5/6 nephrectomy CKD model in vivo. In vitro, H9c2 cells were treated with uremic toxin indoxyl sulfate (IS), with or without NLRP3 inflammasome inhibition, which was achieved by using small interfering RNA (siRNA)mediated knockdown of the NLRP3 gene. Moreover, the activation of nuclear factor KB (NF-KB) signaling and apoptosis marker levels were assessed in the IS-treated H9C2 cells. The results demonstrated that CKD can lead to the development of cardiac contractile dysfunction in vivo associated with the upregulation of NLRP3 inflammasome, IL-1 $\beta, I L-18$, and contribute to the myocardial apoptosis. In vitro experiments showed the upregulation of inflammasome, IL-1 $\beta$, and IL-18 levels, and cell apoptosis in the IS-treated $\mathrm{H} 9 \mathrm{C} 2$ cells through the activation of NF-KB signaling pathway. The transfection of cells with si-NLRP3 was shown to alleviate IL-1 $\beta$, IL-18, and cell apoptosis. Moreover, decreased cell viability induced by IS was shown to be attenuated by IL-1 $\beta$ or IL-18-neutralizing antibody. In summary, CKD can result in the development of cardiac contractile dysfunction associated with the upregulation of NLRP3 inflammasome/IL-1 $\beta /$ IL-18 axis induced by the uremic toxins.

\section{INTRODUCTION}

Inflammasomes are multi-protein platforms that interact with various immune and cellular death pathways $[1,2]$. Among these, the best known is the NLR (nucleotide-binding domain leucine-rich repeat- containing receptor) pyrin domain-containing protein 3 (NLRP3) inflammasome, a crucial factor of innate immunity with a role in many diseases, including microbial infections, rheumatic diseases, diabetes, and atherosclerosis $[3,4]$. The NLRP3 inflammasome is a protein complex that mediates the activation of caspase-1, interleukin- 
$1 \beta$ (IL-1 $\beta$ ), and interleukin-18 (IL-18), generating a feedback mechanism that perpetuates the inflammatory response $[3,5,6]$. Caspase- 1 can be activated within the inflammasome through the binding with the adaptor protein ASC (apoptosis-associated speck-like protein containing a carboxy-terminal CARD), bridging NLRs and caspase-1 [7]. The release of proinflammatory cytokines pro-IL-1 $\beta$ and pro-IL-18 is a complex process involving proteolytic cleavage by caspase-1, which activates IL-1 $\beta$ and IL-18 [8]. IL-1 $\beta$ and IL-18 have been shown to play a role in a variety of cellular processes, including cell apoptosis [9, 10].

NLRP3 inflammasome was recently shown to be present not only in the immune cells, but in the nonimmune cells as well, including myocytes and fibroblasts $[11,12]$. Increased cardiomyocyte apoptosis may lead to cardiac fibrosis, which plays an important role in cardiac remodeling and results in contractile dysfunction or sudden death [13]. Bracey et al. [14] showed that a persistent sterile inflammation and NLRP3 inflammasome presence play a central role in the development of structural cardiomyopathy and heart failure mediated by IL-1 $\beta$. NLRP3 may be involved in the chronic inflammatory state observed in CKD patients undergoing hemodialysis [15]. However, the effects and mechanisms underlying the inflammasome-related cytokine regulation of apoptosis in uremic cardiomyopathy remain unknown.

In this study, cardiac contractile function was evaluated by echocardiography and the expression of NLRP3 inflammasome and related cytokines in heart were assessed by western blotting in a murine sham-operated and 5/6 nephrectomy CKD model in vivo. In vitro, the pathogenic role of NLRP3 inflammasome was investigated by treating H9c2 cells with indoxyl sulfate (IS) with or without NLRP3 inflammasome inhibition, which was achieved by using small interfering RNA (siRNA)mediated knockdown of the NLRP3 gene. To investigate the mechanism of uremic cardiomyopathy induction by the NLRP3 inflammasome, the activation of nuclear factor $\kappa \mathrm{B}(\mathrm{NF}-\kappa \mathrm{B})$ signaling and apoptosis marker levels were assessed in the IS-treated H9c2 cells. The findings described in this study may provide insights into the molecular basis of uremic cardiomyopathy as well as potential targets for the treatment of contractile dysfunction.

\section{RESULTS}

\section{NLRP3 inflammasome-related protein levels were significantly elevated in sera and ventricular tissues of CKD mice}

The schedule of the animal experiments is presented in Figure 1A. Serum biochemical data obtained 3 months after nephrectomy are shown in Figure $1 \mathrm{~B}$ and $1 \mathrm{C}$. The successful induction of experimental renal failure was confirmed by significantly elevated serum blood urea nitrogen (BUN) and creatinine levels in CKD mice. Moreover, echocardiography was used to evaluate and compare cardiac contractile functions in sham-operated and CKD mice. As shown in Figure 1D and 1E, cardiac output and calculated EF were shown to be significantly impaired in CKD mice compared with those in the sham-operated group. As shown in Figure $1 \mathrm{~F}$ and $1 \mathrm{G}$, IL-1 $\beta$ and IL-18 levels were significantly elevated in the sera of CKD mice.

To examine CKD effects on the inflammasome regulation in the cardiac $\mathrm{LV}$ tissues of sham-operated and CKD mice, we analyzed the expression of NLRP3 inflammasome and related proteins, caspase-1 p10, p20, and procaspase-1. the results showed that the NLRP3 inflammasome-related protein levels were increased in hearts of CKD mice (Figure 2). We showed that the impaired cardiac contractile function is associated with the upregulation of NLRP3 inflammasome, IL-1 $\beta$, and IL-18 in CKD mice.

\section{NLRP3 inflammasome-related protein levels were significantly increased in $\mathrm{H} 9 \mathrm{c} 2$ cells}

IS, a circulating uremic toxin, plays a role in the progression of $\mathrm{CKD}$ and can induce $\mathrm{UCM}$ in vivo and in vitro [16-18]. Rat cardiomyocytes, H9c2, were used for studying cellular and molecular mechanisms underlying cardiomyopathy. We treated H9c2 cells with IS $(50-400 \mu \mathrm{M})$ for $24 \mathrm{~h}$, and the expressions of NLRP3 inflammasome in H9c2 cells increased (Figure 3A-3F). Additionally, secreted IL-1 $\beta$ and IL-18 levels were significantly increased in IS-treated H9c2 samples (Figure $3 \mathrm{G}$ and $3 \mathrm{H}$ ), consistent with the in vivo findings.

\section{Uremic toxin induces NLRP3 inflammasome- related protein expression through $\mathrm{NF}-\kappa \mathrm{B}$ signaling pathway in $\mathrm{H9c} 2$ cells}

To investigate whether NLRP3 is involved in the IS-induced maturation and secretion of IL-1 $\beta$ and Il-18, we used specific siRNAs against NLRP3 in the following experiments. By using NLRP3 siRNAs, we knocked down NLRP3 expression, and inhibited the IS-induced NLRP3 inflammasome protein expressions (Figure 4A) and IL-1 $\beta$ or IL-18 secretions (Figure 4B and 4C) in the H9c2 cells.

$\mathrm{NF}-\kappa \mathrm{B}$, a key activator of inflammation, is essential for the expression of NLRP3 inflammasome, pro-IL-1 $\beta$, and pro-IL-18 [1, 19-21]. Inhibitor of kappa B (IкB $\alpha)$ inactivates $\mathrm{NF}-\kappa \mathrm{B}$ transcription factor by keeping it sequestered in an inactive state in the cytoplasm [22]. To elucidate the mechanism underlying the uremic toxinmediated regulation of inflammasome, we investigated $\mathrm{NF}-\kappa \mathrm{B}$ signaling in $\mathrm{H} 9 \mathrm{c} 2$ cells treated with IS. IS treatment was shown to enhance cytosolic Ikb $\alpha$ phosphorylation, and increased the rate of $\mathrm{NF}-\kappa \mathrm{B}$ translocation into the nucleus of H9c2 cells (Figure 4D). 
Early apoptotic protein expression is induced in the cardiac tissues of CKD mice

Mitochondria-mediated apoptotic signaling involving the members of Bcl-2 family is well-characterized, while the caspase cascade is believed to be crucial in the regulation of apoptotic processes in cardiomyopathy $[23,24]$. In our $\mathrm{CKD}$ model, we demonstrated that $\mathrm{Bax} / \mathrm{Bcl}-2$ ratio, cleaved caspase-9, and cleaved caspase- 3 expression levels are elevated in ventricular tissues (Figure 5).

\section{IL-1 $\beta$ and IL-18 neutralizing antibodies} abrogated the effects of uremic toxin on early apoptosis rate and cell viability in $\mathrm{H} 9 \mathrm{c} 2$ cells

IS was shown to induce the apoptosis of kidney mesangial cells [25], whereas the inflammasomerelated proteins induce cell apoptosis in vitro [26, 27]. Controversially, IL-18 inhibits neutrophil apoptosis through PI3K/ERK signal pathway [10]. To determine the effects of uremic toxin on apoptosis rate, we used IL-1 $\beta$ and

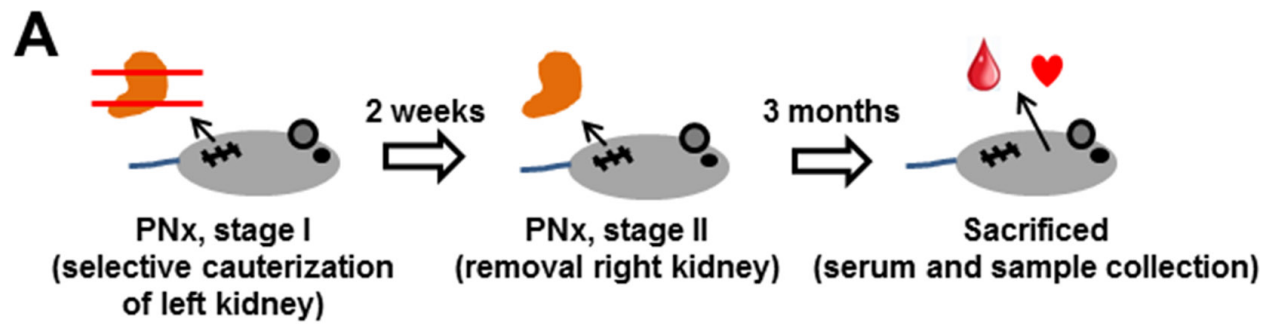

B
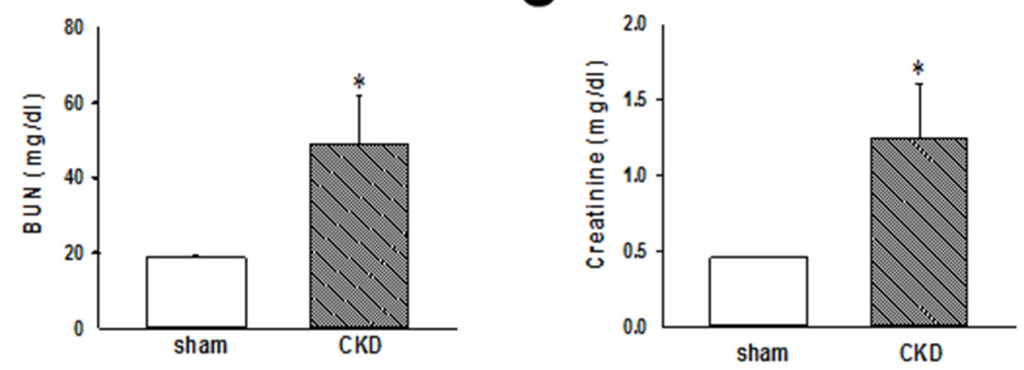

D

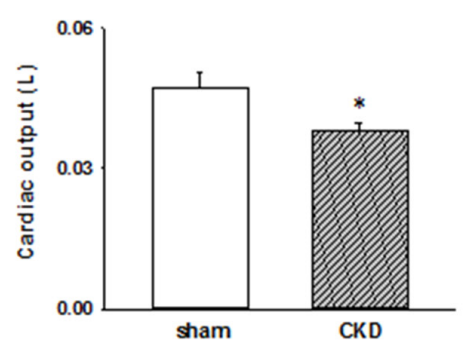

$\mathbf{E}$

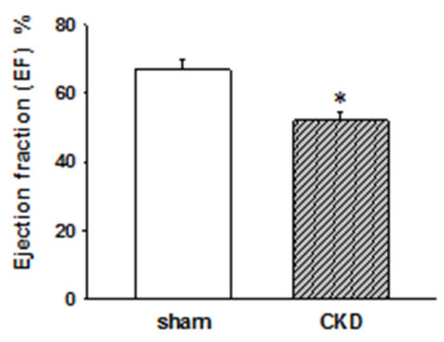

$\mathbf{F}$

G
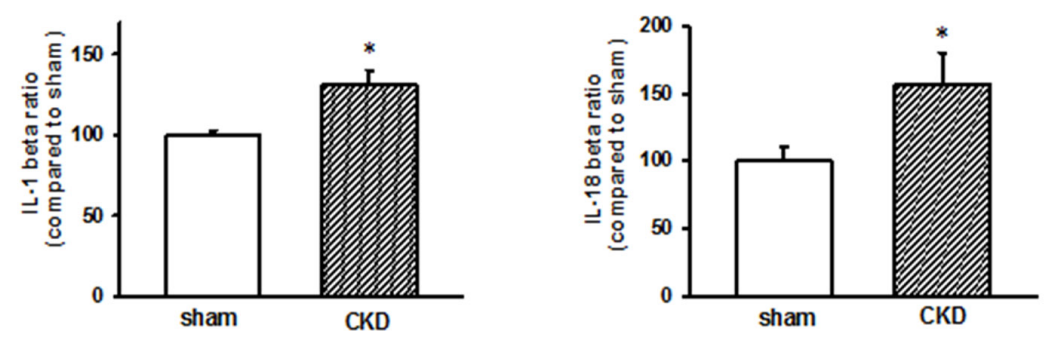

Figure 1: Chronic kidney disease (CKD) effects on heart, biochemical values, and IL-1ß and IL-18 concentrations in mouse sera. (A) Animal experiment schedule. (B, C) Serum blood urea nitrogen (BUN) and creatinine levels in sham and CKD-operated mice. (D, E) Cardiac output and ejection fraction (EF) in sham and CKD mice. (F, G) IL-1 $\beta$ and IL-18 levels in the sera of CKD mice. Values are expressed as mean \pm SEM. ${ }^{*} p<0.05$, compared with the sham-operated group. 
IL-18 neutralizing antibodies, and demonstrated that the IS treatment induces early apoptosis, and not necrosis, in H9c 2 cells (Figure 6A and 6B). The treatment with IL-1 $\beta$ or IL-18-neutralizing antibodies led to a significant inhibition of apoptosis in H9c2 cells (Figure 6C and 6D). MTT assay results showed that the detrimental effect of IS treatment was attenuated by the addition of IL- $1 \beta$ or IL-18 neutralizing antibody (Figure 6E).

\section{Uremic toxin was shown to induce apoptosis through NLRP3 activity modulation}

To investigate the molecular mechanism involved in the regulation of IS-induced $\mathrm{H} 9 \mathrm{c} 2$ apoptosis, we performed western blot analysis of mitochondria-related apoptotic signaling. IS was shown to induce an increase in $\mathrm{Bax} / \mathrm{Bcl}-2$ ratio, cleaved caspase-9, and cleaved caspase-3
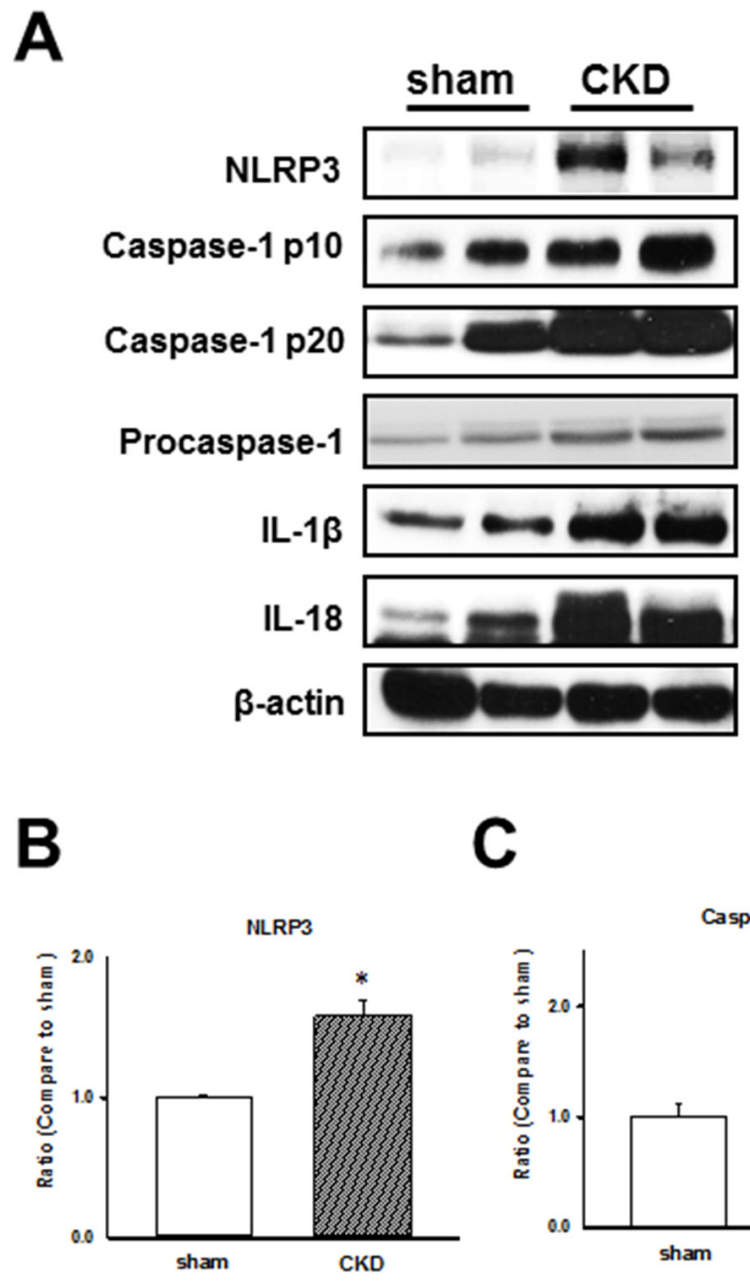

D
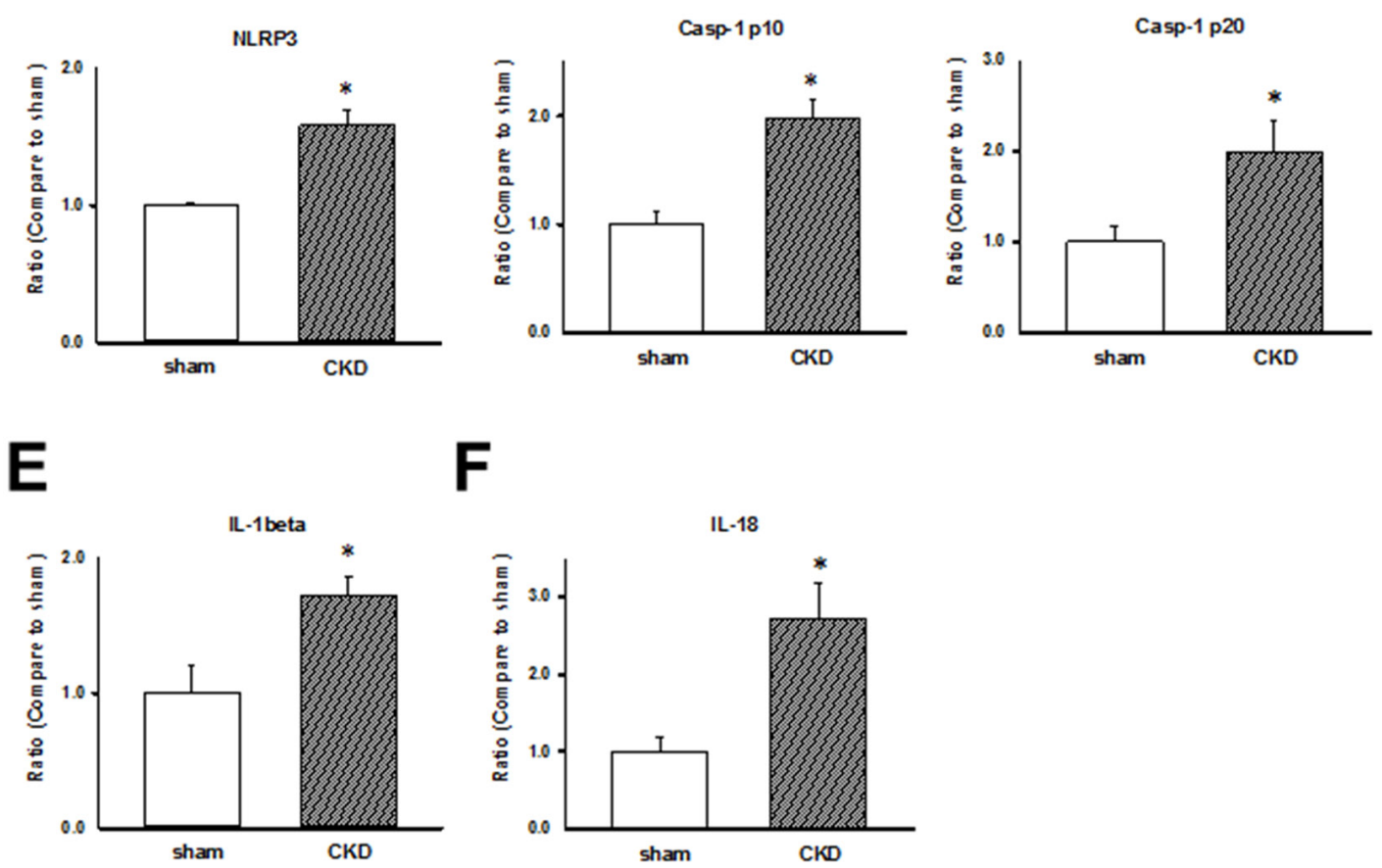

Figure 2: Chronic kidney disease (CKD) effects on inflammasome regulation in mouse ventricular tissues. (A) Representative immunoblots showing the expression of inflammasome-related proteins in CKD mouse heart tissue. (B-F) NLRP3, caspase-1 p10, caspase-1 p20, IL-1 $\beta$, and IL-18 expression levels, normalized to caspase-1 and $\beta$-actin expression levels. The levels are expressed as a relative ratio compared with the corresponding control. Values are expressed as mean \pm SEM. ${ }^{*} p<0.05$, compared with the sham group. 
expressions (Figure 7A). Additionally, NLRP3 knockdown inhibited IS-induced expression of cleaved caspase- 9 and caspase-3 (Figure 7B-7D).

\section{DISCUSSION}

In vivo, $\mathrm{PNx}$-induced $\mathrm{CKD}$ lead to the cardiac contractile dysfunction associated with the upregulation of NLRP3 inflammasome, IL-1 $\beta$, and IL-18 levels, and contribute to myocardial apoptosis. In vitro, the upregulation of these molecules and increased cell apoptosis were observed in the IS-treated H9c2 cells, which was shown to be NF- $\kappa \mathrm{B}-$ mediated. NLRP3 suppression was shown to decrease the expression of IL-1 $\beta$, IL-18, and cell apoptotic markers. Moreover, an IS-induced decrease in cell viability was shown to be attenuated by IL- $1 \beta$ or IL-18 neutralizing antibody. The inhibition of NLRP3 inflammasome-related IL-1 $\beta$ and IL-18 expression may
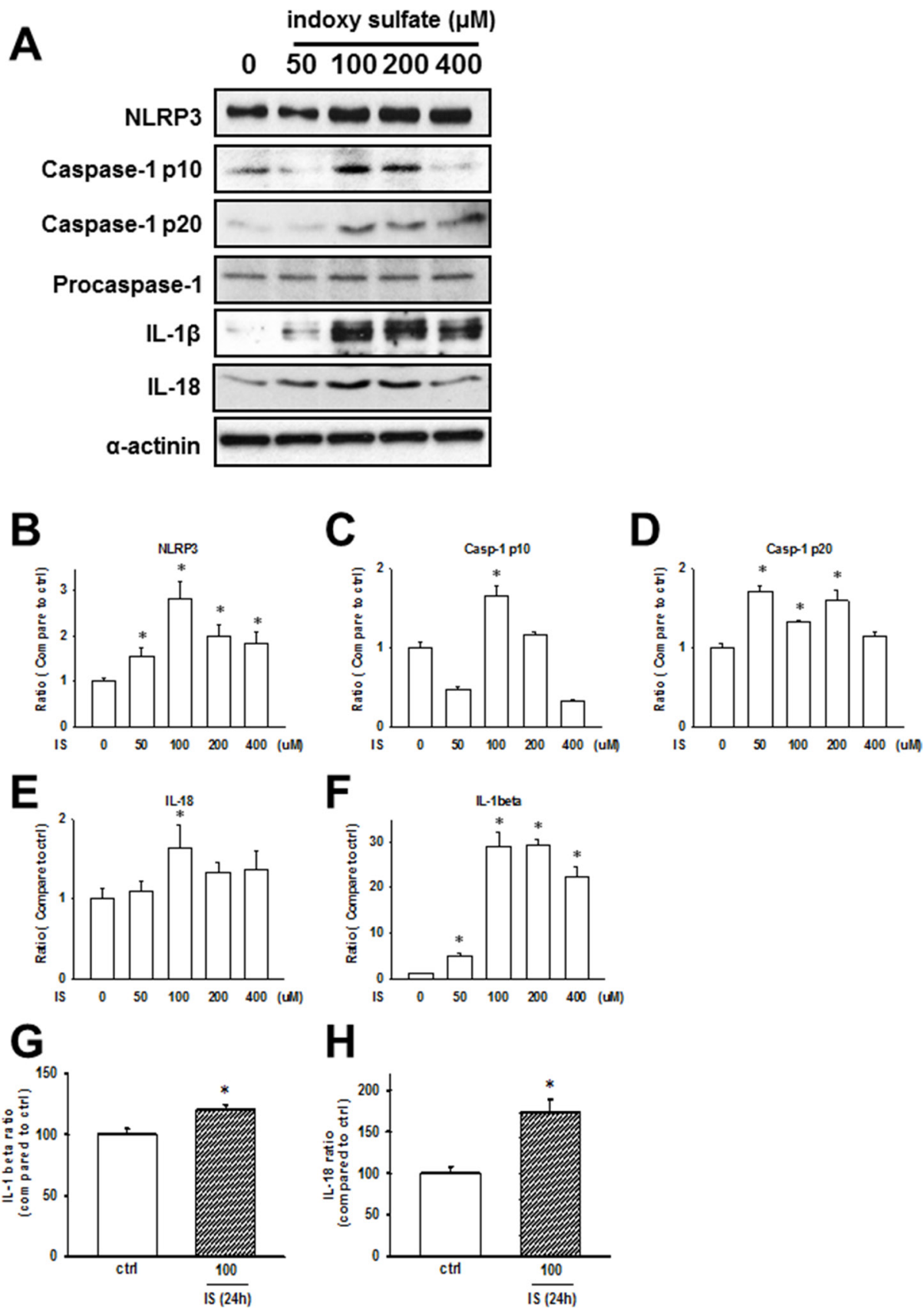

Figure 3: Uremic toxin effects on the inflammasome regulation in H9c2 cells. (A) Inflammasome-related protein expression in the indoxyl sulfate (IS)-treated cells. (B-F) Western blot results quantification. Protein levels were normalized to that of $\alpha$-actinin. $(\mathbf{G}, \mathbf{H})$ IL-1 $\beta$ and IL-18 protein levels in H9c2 cells treated with IS $(100 \mu \mathrm{M})$ for $24 \mathrm{~h}$. Data are presented as mean \pm SEM of three independent experiments. ${ }^{*} p<0.05$, compared with the sham group. 
reduce myocardial apoptosis, potentially preserve cardiac contractile function, and decrease uremic cardiomyopathy induced by uremic toxins.

Chronic kidney disease (CKD) represents a strong and independent risk factor for cardiovascular disease (CVD). Among the potential cardiovascular complications, heart failure is the leading one and its prevalence increases with a decrease in kidney function [28]. Compared with that of the non-CKD patients with similar blood pressure levels, CKD patients have a larger left ventricular mass, suggesting the existence of specific CKD-associated factors that contribute to cardiac remodeling [29]. A fundamental response of cardiomyocytes and left ventricular wall to intrinsic and biochemical stress in CKD is hypertrophy, which at first stages may be compensatory, but it inevitably progresses to dilation and cardiac contractile dysfunction. Structural and functional abnormalities may occur at the earliest stages of CKD, without an obvious CVD [30]. The cardiomyopathy associated with CKD is commonly caused by the immune system activation, and the inflammation
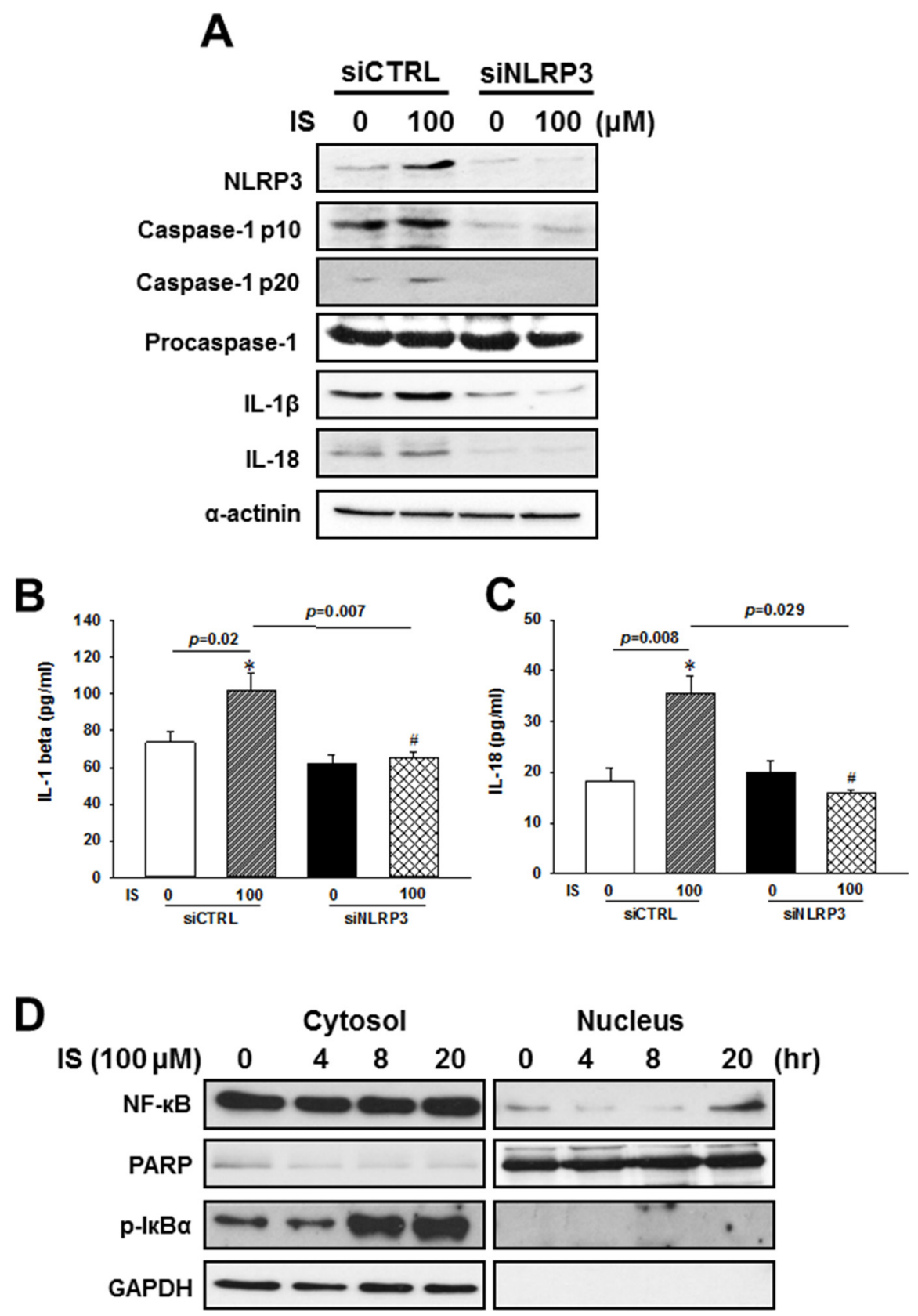

Figure 4: NLRP3 knockdown effects on the regulation of inflammasome-related protein expression in the indoxyl sulfate (IS)-treated H9c2 cells. (A) Western blot analysis of inflammasome-related protein expression in H9c2 cells treated with NLRP3 siRNA and $100 \mu$ M IS. (B, C) Culture medium was collected to determine the IL-1 $\beta$ and IL-18 levels, and apoptosis-related marker expression in NLRP3 knockdown H9c2 cells. (D) NF-кB and Iкb $\alpha$ phosphorylation levels in IS-treated H9c2 cells. The data are presented as mean \pm SEM of three independent experiments. ${ }^{*} p<0.05$, compared with the control. ${ }^{*} p<0.05$, compared with the IS treatment group. 
is considered a non-traditional (CKD-specific) risk factor contributing to CVD development [31, 32].

Inflammasome-related protein activation is required for the maturation and secretion of IL-1 $\beta$ and IL-18 [8]. NLRP3 inflammasome with pro-caspase-1 promotes the secretion of IL-1 $\beta$ and IL-18 $[33,34]$. Activation of mitogen-activated protein kinase (MAPK) and NF- $\kappa B$ signaling pathways is crucial for IL-1 activity, including the production and/or release of nitric oxide (NO), cyclooxygenase-2 (COX-2), and other pro-inflammatory mediators $[35,36]$. IL- $1 \alpha$ and IL- $1 \beta$ are two biologically active isoforms of IL-1, produced as $31 \mathrm{kDa}$ precursors that are stored within the cytosol. Pro-IL- $1 \alpha$ is constitutively expressed, whereas pro-IL-1 $\beta$ is transcribed in response to an inflammatory or infectious stimulus [35]. Caspase-1 processes intracellular pro-IL-1 $\beta$ and is produced from the constitutively expressed $45-\mathrm{kDa}$ cytoplasmic pro-enzyme, pro-caspase-1, which requires
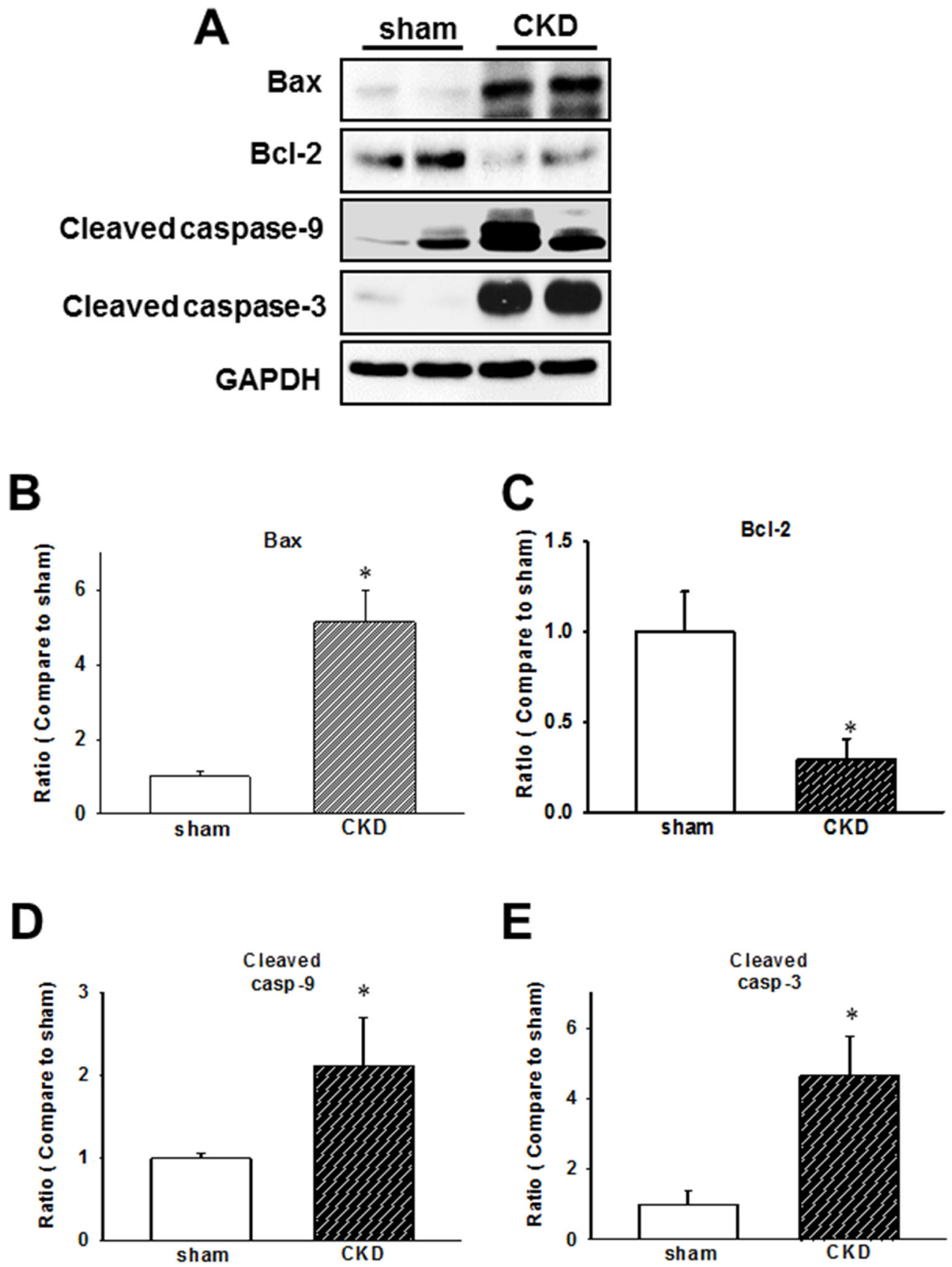

Figure 5: Chronic kidney disease (CKD) effects on the expression of early apoptotic proteins in mouse cardiac tissues. (A) Expression of early apoptotic proteins in the heart of CKD mice. (B-E) Quantification of protein levels by using computer-assisted densitometry, and Gapdh levels for normalization. Data are expressed as percentages relative to the corresponding sham control. Values are expressed as mean \pm SEM. ${ }^{*} p<0.05$, compared with the sham group. 
post-translational processing to form 20- and $10-\mathrm{kDa}$ active forms of caspase-1 [37], following the assembly of the NLRP3 inflammasome. Low active caspase-1, IL-1 $\beta$, and IL-18 levels induce cytokine production, but higher levels of these molecules can induce cell death or pyroptosis [38].

IL-18 is a key mediator in the host response to infection and the inflammatory response [35, 39]. It is constitutively expressed as a precursor, pro-IL 18
[40], cleaved by either caspase- 1 or proteinase- 3 into its active form, and released into the extracellular space together with mature IL-1 $\beta$. Growing evidence suggests that the inflammasome and the IL-1 $/$ / IL-18 axis play an integral part in the pathogenesis of many acute and chronic conditions [41]. Here, 5/6 PNx was shown to induce IL- $1 \beta$ and IL-18 expression in CKD mice and IStreated H9c2 cells. Furthermore, the expression of NLRP3 inflammasome-related proteins and apoptotic markers in
A

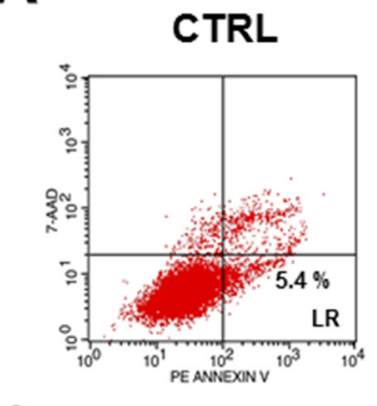

C

IS+IL1 $\beta$ Ab

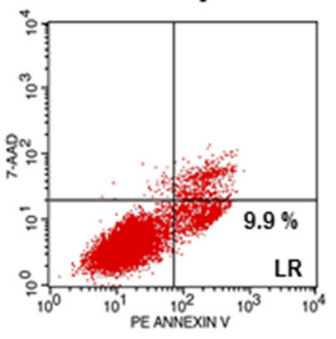

B

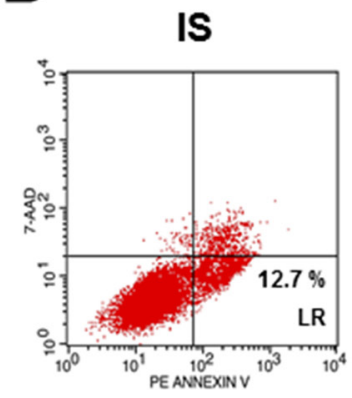

D
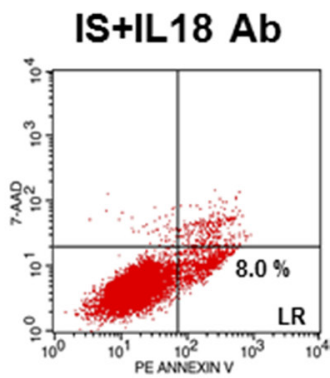

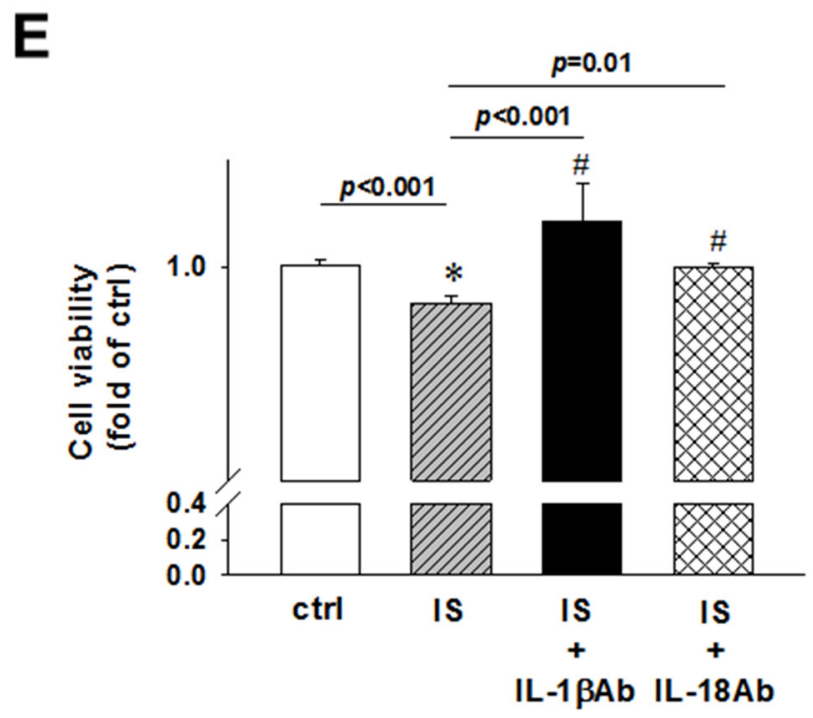

Figure 6: IL-1 $\beta$ and IL-18 neutralizing antibody effects on uremic toxin IS-induced early apoptosis and cell viability of H9c2 cells. (A) Control. (B) Indoxyl sulfate (IS)-treated group. (C) IS- and IL-1 $\beta$ antibody-treated group. (D) IS- and IL-18 antibodytreated group. H9c2 cells were treated and stained for flow cytometry analysis. Lower right, early apoptosis rate of H9c2 cells. (E) MTT assay, showing the viability of IL-1 $\beta$ and IL-18 antibody-treated cells. All data are presented as mean \pm SEM. ns=no significance. 
CKD mouse hearts and the IS-treated H9c2 cells was shown to be upregulated. NLRP3 siRNA knockdown had an opposite effect on the cleaved caspase- 9 and caspase- 3 expression levels, indicating that IL- $1 \beta$ and IL-18 may bind to the receptors in an autocrine/paracrine manner and induce $\mathrm{H} 9 \mathrm{c} 2$ cell apoptosis. These data suggest that the induction of proinflammatory cytokine expression by uremic toxins in CKD can lead to a persistent inflammation in myocardium and myocardial apoptosis, which contributes to uremic cardiomyopathy and cardiac contractile dysfunction development. Cardiomyocyte apoptosis leads to the loss of myocardial contractile unit and finally results in cardiac contractile dysfunction in uremic cardiomyopathy. A decrease in cell viability of the IS-treated H9c2 cells was shown to be attenuated by anti-IL-1 $\beta$ or -IL-18 antibodies. Inflammasome and the IL-1 $\beta /$ IL-18 axis may represent therapeutic targets for the treatment of CKD-related cardiac contractile dysfunction.

A

indoxy sulfate (IS)
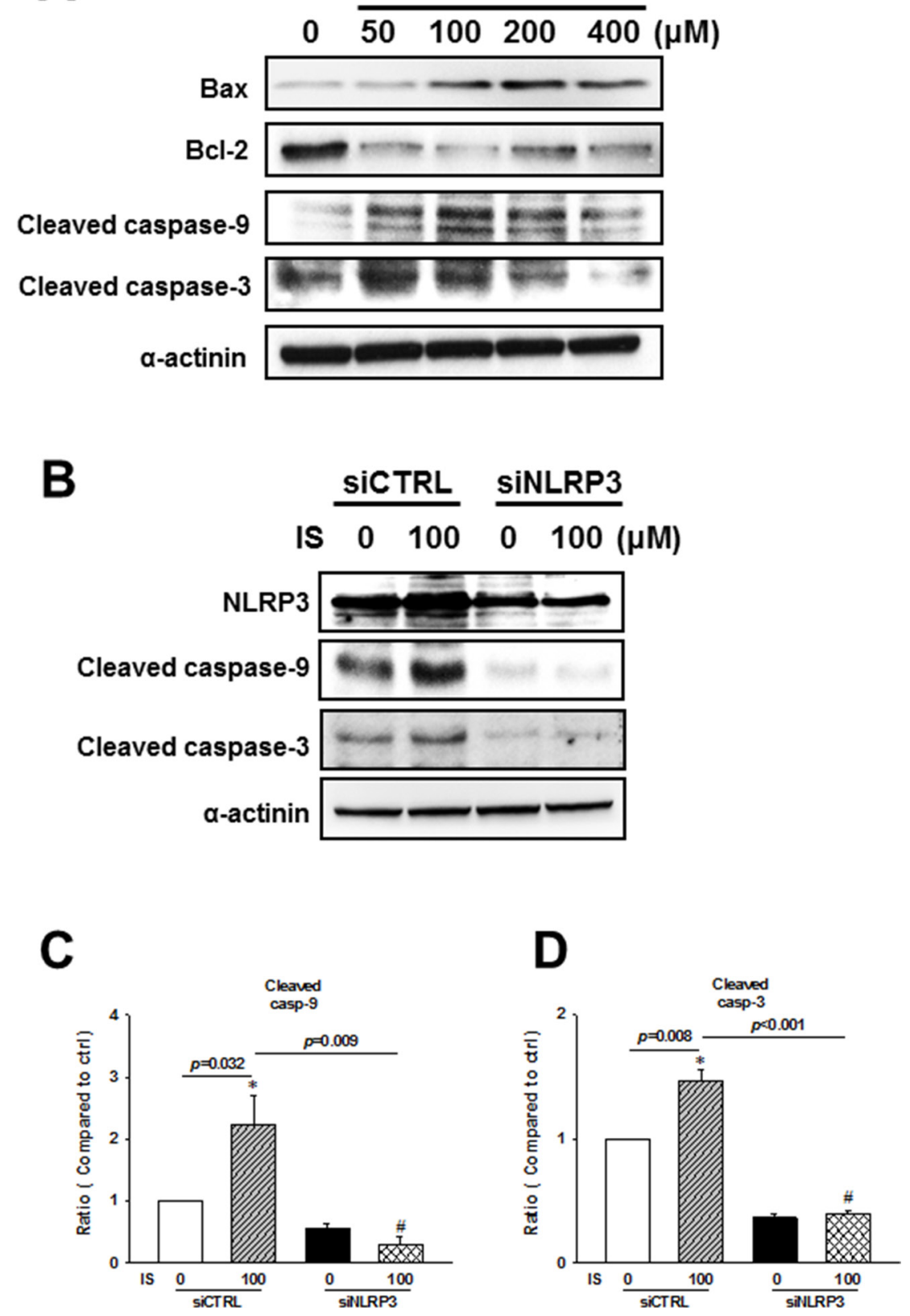

Figure 7: NLRP3 knockdown effects on the apoptosis-related protein expression in indoxyl sulfate (IS)-treated H9c2 cells. (A) Expression levels of early apoptosis-related proteins in the IS-treated cells. (B-D) H9c2 cells were treated with NLRP3 siRNA or scrambled siRNA for $24 \mathrm{~h}$, and then stimulated with IS for $48 \mathrm{~h}$, and cleaved caspase-9 and caspase-3 levels were determined in H9c2 cells. Data are presented as mean \pm SEM of three independent experiments. ${ }^{*} p<0.05$, compared with the control group. ${ }^{\#} p<0.05$, compared with the IS treatment group. 
However, the mechanisms involved in the protection against CKD-induced apoptosis by inflammasome inhibition should be further elucidated.

NLRP3 inflammasome is not limited by traditional microbial stimuli of innate immunity and its connection with autophagy, fibrosis, and pro-inflammatory cytokines has broader implications for a variety of kidney disease [42]. This sterile renal inflammation is considered a central therapeutic target for the reduction of chronic renal injury and decline in CKD progression [43]. Persistent inflammation leads to the progressive renal fibrosis and loss of renal function, together with the induction of other CKD-related complications, such as cardiovascular disorders [44-46]. The NLRP3 inflammasome is activated in the ischemic heart and the inhibition of the NLRP3initiated inflammasome during experimental myocardial infarction minimizes the activation of caspase- 1 in the heart and improves LV remodeling and function [14, 47-50]. Moreover, NLRP3 inflammasome is also involved in the development of myocardial dysfunction with sepsis and diabetes in animal models $[11,12]$. We showed that the uremic toxin-related NLRP3 inflammasome upregulation may be extrapolated to uremic cardiomyopathy and cardiac contractile dysfunction.

IS, a tryptophan metabolite, is a representative uremic toxin, which may initiate cellular responses, phagocytosis, and particularly apoptosis [51]. The accumulation of uremic toxins impairs hemostasis and increases the rate of infections and malignancy due to its effects on the immune system [52]. In uremic patients, IS serum levels are markedly increased, which induces oxidative stress [53]. Oxidative stress and chronic inflammation are strongly related and contribute to longterm complications in HD patients, $[54,55]$. In this study, CKD induced the upregulation of inflammasome-related protein expressions and apoptotic signaling pathway members, activating mitochondria-associated apoptotic signaling, through the modulation of Bcl-2 family members and caspase cascade in CKD mouse hearts and IS-treated H9c2 cells. Uremic toxin was shown to regulate inflammasome-related protein expressions through the activation of NF- $\mathrm{KB}$-mediated signaling in $\mathrm{H} 9 \mathrm{c} 2$ cells. Our results indicate the crucial role of IS in the regulation of NLRP3 inflammasome in uremic cardiomyopathy.

There are some limitations in this study. First, although we demonstrated IL-1 $\beta$ and IL-18 may bind to the receptors in an autocrine/paracrine manner and induce $\mathrm{H} 9 \mathrm{c} 2$ cell apoptosis, cardiomyocytes are not the only source of IL-1 $\beta$ and IL-18. The effect of IS on other immune cells should also be response for the elevation of IL-1 $\beta$ and IL-18 in serum. Second, there are multiple signaling pathways involved in the detrimental effects of IS and therefore lead to uremic cardiomyopathy and IS in not the only uremic toxin in CKD. Third, cardiac contractile dysfunction is a complex disease entity in patients with CKD. Several CKD-specific factors, including abnormal calcium and phosphate metabolism, uremic toxins, anemia, inadequate dialysis, and increased oxidative stress, have been shown to contribute to the development of uremic cardiomyopathy. Although we clearly demonstrated the role of NLRP3 inflammasome in the development of cardiac contractile dysfunction, more extensive in vivo and in vitro studies are necessary to investigate the complexity of this disease entity.

In conclusion, The NLRP3 inflammasome is increasingly being recognized as an integral component of the pathogenesis of many renal diseases and their complications. Taken together, we here show a possible mechanisms underlying the IS-induced inflammasome expression and cardiomyocyte apoptosis (Figure 8). IS treatment was shown to increase the expression of inflammasome by inducing cytosolic I $\mathrm{b} \alpha$ phosphorylation and NF- $\mathrm{NB}$ nuclear translocation, which may lead to a subsequent binding of this molecule to the NLRP3 promoter, further inducing IL-1 $\beta$ and IL-18 expression and secretion. This may, subsequently, contribute to H9c2 cell apoptosis. The results of this study may help develop a novel strategy for the treatment of patients with UCM. Inflammasome may represent a promising therapeutic target for the treatment of CKD-related cardiomyopathy.

\section{MATERIALS AND METHODS}

\section{Animal experiments}

CKD cardiomyopathy was induced in vivo using partial nephrectomy (PNx) at a C57BL/6J background as described previously $[56,57]$. Animal experiments were approved by the local animal care committee of National Defense Medical Center (IACUC-16-266). Animals were housed in a light- and temperature-controlled room with free access to deionized drinking water and standard chow consisting of $0.28 \%$ (wt/wt) $\mathrm{NaCl}, 1.00 \%$ (wt/wt) Ca, $0.22 \%$ (wt/wt) Mg (LabDiet, Richmond, IN, USA). After the acclimatization, mice were randomly assigned to two groups: sham-operated and PNx mice. PNx was performed on 4-month-old male C57BL/6 mice by selective cauterization of the entire upper and lower poles of the left kidney via a Bovie high-temperature fine-tip cautery (Aaron Medical, St. Petersburg, FL, USA), leaving an intact 2-mm segment around the hilum (PNx, stage I). This procedure was followed by the removal of the right kidney after 2 weeks (PNx, stage II). The animals were euthanized 3 months after sham operation or PNx by $\mathrm{CO}_{2}$ inhalation. Blood was collected and the hearts were dissected and processed for further analyses.

\section{Echocardiography}

Echocardiography was performed using a Philips iE33 ultrasound imaging system (Philips Medical Systems, Best, Netherlands) equipped with a 7-15 MHz 
linear array transducer. Anesthesia was performed using $3 \%$ isoflurane inhalation, until animals were sedated, and then it was maintained with $1 \%$ isoflurane during the echocardiographic examination. After obtaining twodimensional left ventricular () short-axis images, M-mode traces were acquired for the measurement of LV wall thickness and chamber dimensions at diastole and systole, echocardiography-derived ejection fraction (EF). All measurements were averaged for five consecutive cardiac cycles and were performed in a blinded manner by an experienced technician (Y-H Chen).

\section{Cell culture and treatment}

The H9c2 rat myoblast cell line (BCRC60096) was purchased from the Bioresource Collection and Research Center of the Food Industry Research and Development Institute (Taipei, Taiwan). Cells were grown in Dulbecco's Modified Eagle's Medium (DMEM) supplemented with $10 \%$ fetal bovine serum (FBS), $150 \mathrm{U} / \mathrm{mL}$ penicillin, and $150 \mathrm{mg} / \mathrm{mL}$ streptomycin. Cells were incubated at $37^{\circ} \mathrm{C}$ in $5 \% \mathrm{CO}_{2} / 95 \%$ air. Confluent cells were detached using a $0.05 \%$ trypsin $/ 0.02 \%$ EDTA solution and subcultured to the second passage in six-well culture plates. H9c2 cells were treated with IS $(50-400 \mu \mathrm{M})$ in the presence or absence of IL- $1 \beta$ or IL-18 neutralizing antibody $(1 \mu \mathrm{g} / \mathrm{mL})$.

\section{IL-1 $\beta$ and IL-18 concentration measurements using enzyme-linked immunosorbent assay (ELISA)}

IL-1 $\beta$ (Koma Biotech Inc., Seoul, Korea) and IL-18 (MBL Int., Woburn, MA, USA) concentrations in the mouse sera or $\mathrm{H} 9 \mathrm{c} 2$ conditioned media were determined using the ELISA kits according to the manufacturers' instructions. Cell culture media were collected and centrifuged at $3000 \mathrm{rpm}$ for $1 \mathrm{~min}$ at $4^{\circ} \mathrm{C}$. The supernatants were collected, and the concentrations of IL- $1 \beta$ and IL-18 were determined.

\section{Nuclear extraction}

To examine the effect of CKD on nuclear translocation of NF- $\kappa \mathrm{B}$ (p65), the NE-PER nuclear and cytoplasmic extraction reagents (Thermo Fisher Scientific, Rockford, IL, USA) were used and the extraction was performed according to the manufacturer's protocol. Briefly, cell pellets were resuspended in the cytoplasmic

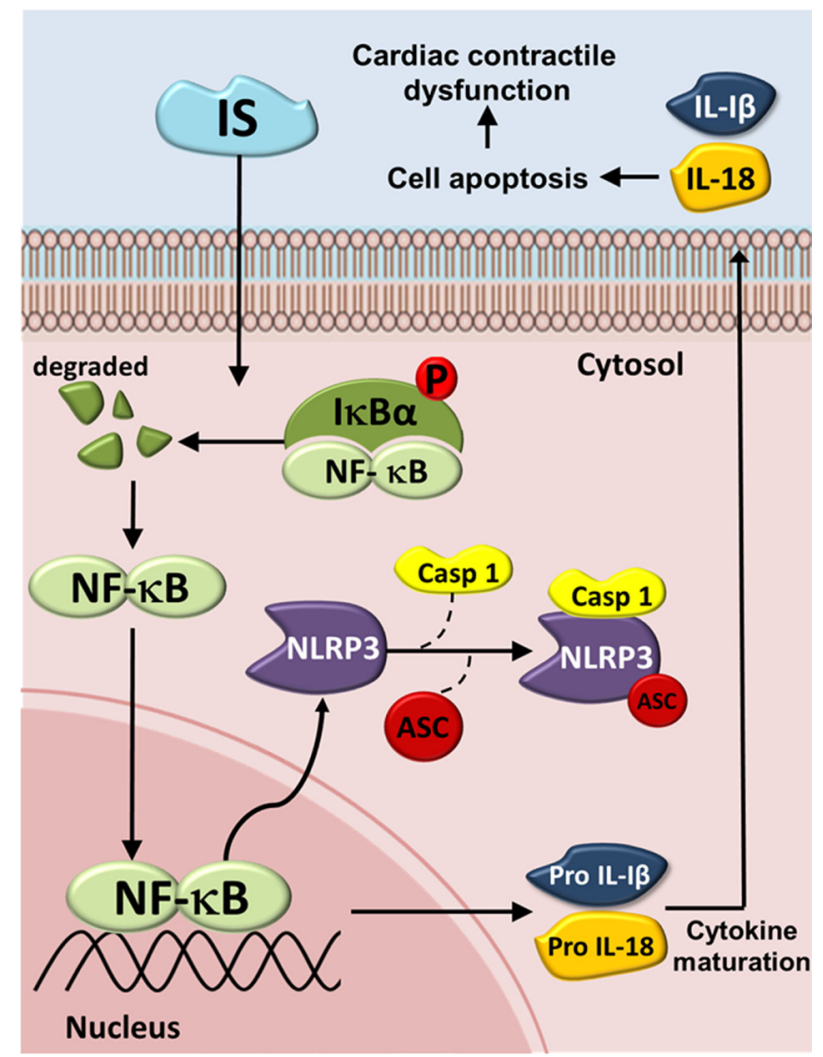

Figure 8: Schematic diagram of molecules mediating indoxyl sulfate (IS) effects on inflammasome in UCM. The ISinduced increase in the expression of IL-1 $\beta$ and IL-18 may be mediated through the NLRP3/caspase-1 signaling pathway, and the secreted IL-1 $\beta$ and IL-18 may bind to their receptors, inducing cell apoptosis by activating the early apoptotic cascade. IS = Indoxyl sulfate; Iкb $\alpha=$ inhibitor of kappa B; NF-кB = Nuclear factor kappa B; NLRP3 = NLR pyrin domain-containing protein 3; ASC = Apoptosisassociated speck-like protein; Casp $1=$ Caspase-1; IL-1 $\beta=$ Interleukin-1 $\beta$; IL-18 = Interleukin-18. 
extraction reagent I buffer containing protease inhibitor cocktail (Sigma-Aldrich), and then the cells were lysed in the cytoplasmic extraction reagent II buffer, to release cytoplasmic proteins. After the centrifugation at $16,000 \times g$ for $5 \mathrm{~min}$ at $4^{\circ} \mathrm{C}$, the insoluble pellet, containing nuclear proteins, was washed with ice-cold phosphate-buffered saline (PBS) two times and then incubated in nuclear extraction reagent buffer containing protease inhibitor cocktail (Sigma-Aldrich).

\section{NLRP3 knockdown by siRNA}

Cells were transfected with scrambled control siRNA (cat. D-001810-10, Dharmacon, Lafayette, CO, USA) or NLRP3-pooled specific siRNA (final concentration, 25 nM; cat. L-084509-02-0005, Dharmacon, Lafayette, CO, USA) by using INTERFERin transfection reagent (PolyPlus Transfection, Illkirch, France) according to manufacturer's instructions.

\section{MTT assay}

The MTT (3-(4,5-dimethylthiazol-2-yl)-2,5diphenyltetrazolium bromide) tetrazolium reduction assay is based on the mitochondrial activity, which leads to the production of water-insoluble formazan salt. Cells were seeded in 24-well plates and treated. Afterward, $10 \mu \mathrm{L}$ MTT (final concentration, $0.5 \mathrm{mg} / \mathrm{mL}$ ) were added to each well, followed by the incubation for $4 \mathrm{~h}$ at $37^{\circ} \mathrm{C}$. Culture medium was removed by aspiration, and the cells were washed twice with PBS, after which $100 \mu \mathrm{L}$ of dimethyl sulfoxide (DMSO) were added to dissolve blue formazan in viable cells. Absorbance was read at $570 \mathrm{~nm}$ using a microplate reader (Sunrise, Tecan, Germany). Cells incubated with control medium were considered 100\% viable. Cell viability percentage $=$ the optical density (OD) value of each treated group/OD value of control group $\times 100 \%$. The concentration of icariin used in further experiments was selected based on the MTT results.

\section{Apoptosis and necrosis evaluation using flow cytometry}

Apoptotic cell death rate was assessed by using the annexin V-phycoerythrin (PE) apoptosis detection kit (BD Pharmingen, San Diego, CA, USA) according to the manufacturer's protocol. Briefly, the cells were harvested by trypsinization, centrifuged, and washed twice in cold PBS. Afterwards, they were resuspended in $100 \mu \mathrm{L}$ of $1 \times$ binding buffer at a concentration of $1 \times 10^{6}$ cells $/ \mathrm{mL}$. After the addition of $5 \mu \mathrm{L}$ of annexin V PE and $5 \mu \mathrm{L}$ of 7-amino-actinomycin (7-AAD), the cells were gently vortexed and incubated for $15 \mathrm{~min}$ at room temperature $\left(25^{\circ} \mathrm{C}\right)$ in dark. The cell samples were diluted in $400 \mu \mathrm{L}$ of $1 \times$ binding buffer and analyzed by flow cytometry within $1 \mathrm{~h}$ using a Nucleocounter NC-3000 instrument
(ChemoMetec Inc, Allerod, Denmark). Compensation and plot quadrants were determined by using the unstained cells and cells stained with either annexin V-PE or 7-AAD alone. The gating strategy was as follows: an initial forward scatter $v s$. side scatter gating, to exclude debris, followed by annexin V-PE and 7-AAD gating, to distinguish the apoptotic from viable cells. By using this gating strategy, annexin V-negative/7-ADD negative cells were defined as viable, annexin-positive/7-AAD negative cells as early apoptotic, annexin V-negative/7-ADDpositive cells as dead cells, and annexin V-positive/7ADD-positive cells as late apoptotic or necrotic cells.

\section{Western blot analysis}

Tissues were homogenized in lysis buffer (1 M Tris-Cl PH 8.0, 1.2 M NaCl, 0.5\% v/v Nonidet P-40) with $10 \mu \mathrm{L} / \mathrm{mL}$ of protease inhibitor cocktail freshly added (Sigma-Aldrich) for $15 \mathrm{~min}$ on ice, followed by the centrifugation at $14000 \times \mathrm{g}$ for $15 \mathrm{~min}$ at $4^{\circ} \mathrm{C}$. Protein content was determined in the supernatants, according to the manufacturer's instructions (Bio-Rad). Samples were boiled for $5 \mathrm{~min}$ in reducing sample buffer with 2-mercaptoethanol $(5 \mu \mathrm{L} / 100 \mathrm{~mL})$ and then resolved using $10 \%$ SDS-PAGE. Separated proteins were transferred to nitrocellulose membranes, which were then blocked in $5 \%$ milk in PBS with $0.01 \%$ Tween-20 (PBST) overnight at $4{ }^{\circ} \mathrm{C}$. After blocking, the membranes were incubated in diluted primary antibody solutions for $1 \mathrm{~h}$ at room temperature, which was followed by washing in PBST for $15 \mathrm{~min}$, three times. Membranes were then incubated with the diluted (1:10000) secondary horseradish peroxidase (HRP)-conjugated antibodies for $1 \mathrm{~h}$, followed by the washing in PBST for 15 min three times. ECL Plus western blotting detection reagents (Amersham Biosciences) and Kodak X-ray films were used for the visualization of protein bands. Primary antibodies diluted in bovine serum albumin (BSA) were as follows: rabbit anti-NLRP3 (Cell Signaling Technology), rabbit anticaspase-1 p10 (Santa Cruz Biotechnology, USA), goat anti-caspase-1 p20 (Santa Cruz Biotechnology, USA), rabbit anti-caspase-1 (Proteintech, China), mouse anti-IL$1 \beta$ (Santa Cruz Biotechnology, USA), mouse anti-IL-18 antibody (Santa Cruz Biotechnology, USA), rabbit antiBcl-2 (Proteintech, China), mouse anti-caspase-9 (Cell Signaling Technology, USA), rabbit anti-caspase-3 (Cell Signaling Technology, USA), mouse anti-p-Ікь $\alpha$ (Santa Cruz Biotechnology, USA), rabbit anti-NF-кB (Cell Signaling Technology, USA), rabbit anti-glyceraldehyde3-phosphate dehydrogenase (GAPDH) (MBL, Japan), and mouse anti- $\beta$-actin (Sigma-Aldrich, USA) antibodies. Protein band intensity in each blot was normalized to the levels of Gapdh, and relative protein levels were quantified using ImageJ software. 


\section{Statistical analysis}

Data were expressed as mean \pm standard error of the mean (SEM). Differences between groups were examined for statistical significance using Kruskal-Wallis test, if appropriate. Statistical significance was set at $p$-values $<0.05$.

\section{Abbreviations}

ASC: apoptosis-associated speck-like protein; BUN: blood urea nitrogen; Casp1: Caspase 1; CKD: chronic kidney disease; CVD: cardiovascular disease; EF: ejection fraction; GAPDH: glyceraldehyde-3-phosphate dehydrogenase; IL: interleukin; IL-1 $\beta$ : interleukin-1 $\beta$; IL18: interleukin-18; IS: indoxyl sulfate; LV: left ventricle; LVH: left ventricular hypertrophy; MAPK: mitogenactivated protein kinase; MTT: 3- (4,5-dimethylthiazol2-yl)-2,5-diphenyltetrazolium bromide; NF- $\mathrm{kB}$ : nuclear factor $\kappa \mathrm{B}$; NO: nitric oxide; NLR: nucleotide-binding domain leucine-rich repeat-containing receptor; NLRP3: NLR pyrin domain-containing protein 3; PARP: poly ADPribose polymerase; PNx: partial nephrectomy; siRNA: short interfering RNA; UCM: uremic cardiomyopathy

\section{ACKNOWLEDGMENTS}

We are grateful to Dr. Yu-Ching Chou (School of Public Health, National Defense Medical Center, Taipei, Taiwan) for his kind assistance in the statistical analyses.

\section{CONFLICTS OF INTEREST}

None declared.

\section{FUNDING}

This work was supported by the National Science Council of Taiwan (MOST 104-2314-B-016-042-MY2 and MOST 105-2811-B-016-019); Tri-Service General Hospital (TSGH-C106-005-007-S05) and Taipei, Taichung, Kaohsiung Veterans General Hospital, Tri-Service General Hospital, National Defense Medical Center, Academia Sinica Joint Research Program (VTA 105-V1-4-2).

\section{REFERENCES}

1. Franchi L, Munoz-Planillo R, Nunez G. Sensing and reacting to microbes through the inflammasomes. Nat Immunol. 2012; 13:325-332.

2. Schroder K, Zhou R, Tschopp J. The NLRP3 inflammasome: a sensor for metabolic danger? Science. 2010; 327:296-300.

3. Strowig $\mathrm{T}$, Henao-Mejia J, Elinav E, Flavell R. Inflammasomes in health and disease. Nature. 2012; 481:278-286.
4. Lamkanfi M, Dixit VM. Inflammasomes and their roles in health and disease. Annu Rev Cell Dev Biol. 2012; 28:137-161.

5. Jin C, Flavell RA. Molecular mechanism of NLRP3 inflammasome activation. J Clin Immunol. 2010; 30:628-631.

6. Martinon F, Tschopp J. Inflammatory caspases: linking an intracellular innate immune system to autoinflammatory diseases. Cell. 2004; 117:561-574.

7. Davis BK, Wen H, Ting JP. The inflammasome NLRs in immunity, inflammation, and associated diseases. Annu Rev Immunol. 2011; 29:707-735.

8. Schroder K, Tschopp J. The inflammasomes. Cell. 2010; 140:821-832.

9. Wang XJ, Kong KM, Qi WL, Ye WL, Song PS. Interleukin-1 beta induction of neuron apoptosis depends on p38 mitogen-activated protein kinase activity after spinal cord injury. Acta Pharmacol Sin. 2005; 26:934-942.

10. Hirata J, Kotani J, Aoyama M, Kashiwamura S, Ueda H, Kuroda Y, Usami M, Okamura H, Marukawa S. A role for IL-18 in human neutrophil apoptosis. Shock. 2008; 30:628-633.

11. Luo B, Li B, Wang W, Liu X, Xia Y, Zhang C, Zhang M, Zhang Y, An F. NLRP3 gene silencing ameliorates diabetic cardiomyopathy in a type 2 diabetes rat model. PloS One. 2014; 9:e104771.

12. Zhang W, Xu X, Kao R, Mele T, Kvietys P, Martin CM, Rui T. Cardiac fibroblasts contribute to myocardial dysfunction in mice with sepsis: the role of NLRP3 inflammasome activation. PloS One. 2014; 9:e107639.

13. Wencker D, Chandra M, Nguyen K, Miao W, Garantziotis S, Factor SM, Shirani J, Armstrong RC, Kitsis RN. A mechanistic role for cardiac myocyte apoptosis in heart failure. J Clin Invest. 2003; 111:1497-1504.

14. Bracey NA, Beck PL, Muruve DA, Hirota SA, Guo J, Jabagi H, Wright JR Jr, Macdonald JA, LeesMiller JP, Roach D, Semeniuk LM, Duff HJ. The Nlrp3 inflammasome promotes myocardial dysfunction in structural cardiomyopathy through interleukin-1beta. Exp Physiol. 2013; 98:462-472.

15. Granata S, Masola V, Zoratti E, Scupoli MT, Baruzzi A, Messa M, Sallustio F, Gesualdo L, Lupo A, Zaza G. NLRP3 inflammasome activation in dialyzed chronic kidney disease patients. PloS One. 2015; 10:e122272.

16. Tang WH, Wang CP, Chung FM, Huang LL, Yu TH, Hung WC, Lu LF, Chen PY, Luo CH, Lee KT, Lee YJ, Lai WT. Uremic retention solute indoxyl sulfate level is associated with prolonged QTc interval in early CKD patients. PloS One. 2015; 10:e0119545.

17. Niwa T, Ise M. Indoxyl sulfate, a circulating uremic toxin, stimulates the progression of glomerular sclerosis. J Lab Clin Med. 1994; 124:96-104.

18. Miyazaki T, Ise M, Seo H, Niwa T. Indoxyl sulfate increases the gene expressions of TGF-beta 1, TIMP-1 and pro-alpha 
1(I) collagen in uremic rat kidneys. Kidney Int Suppl. 1997; 62:S15-S22.

19. Vallabhapurapu S, Karin M. Regulation and function of NF-kappaB transcription factors in the immune system. Annu Rev Immunol. 2009; 27:693-733 .

20. Bauernfeind FG, Horvath G, Stutz A, Alnemri ES, MacDonald K, Speert D, Fernandes-Alnemri T, Wu J, Monks BG, Fitzgerald KA, Hornung V, Latz E. Cutting edge: NF-kappaB activating pattern recognition and cytokine receptors license NLRP3 inflammasome activation by regulating NLRP3 expression. J Immunol. 2009; 183:787-791.

21. Franchi L, Eigenbrod T, Munoz-Planillo R, Ozkurede U, Kim YG, Chakrabarti A, Gale M Jr, Silverman RH, Colonna M, Akira S, Nunez G. Cytosolic double-stranded RNA activates the NLRP3 inflammasome via MAVSinduced membrane permeabilization and $\mathrm{K}+$ efflux. J. Immunol. 2014; 193:4214-4222.

22. Jacobs MD, Harrison SC. Structure of an IkappaBalpha/ NF-kappaB complex. Cell. 1998; 95:749-758.

23. Shi J, Abdelwahid E, Wei L. Apoptosis in anthracycline cardiomyopathy. Curr Pediatr Rev. 2011; 7:329-336.

24. Kwak HB. Effects of aging and exercise training on apoptosis in the heart. J Exerc Rehabil. 2013; 9:212-219.

25. Wang WJ, Cheng MH, Sun MF, Hsu SF, Weng CS. Indoxyl sulfate induces renin release and apoptosis of kidney mesangial cells. J Toxicol Sci. 2014; 39:637-643.

26. Miura M, Zhu H, Rotello R, Hartwieg EA, Yuan J. Induction of apoptosis in fibroblasts by IL-1 beta-converting enzyme, a mammalian homolog of the $\mathrm{C}$. elegans cell death gene ced-3. Cell. 1993; 75:653-660.

27. Finotto S, Siebler J, Hausding M, Schipp M, Wirtz S, Klein S, Protschka M, Doganci A, Lehr HA, Trautwein C, Khosravi-Far R, Strand D, Lohse A, et al. Severe hepatic injury in interleukin 18 (IL-18) transgenic mice: a key role for IL-18 in regulating hepatocyte apoptosis in vivo. Gut. 2004; 53:392-400.

28. Bagshaw SM, Cruz DN, Aspromonte N, Daliento L, Ronco F, Sheinfeld G, Anker SD, Anand I, Bellomo R, Berl T, Bobek I, Davenport A, Haapio M, et al. Epidemiology of cardio-renal syndromes: Workgroup statements from the 7th ADQI Consensus Conference. Nephrol Dial Transplant. 2010; 1406-1416.

29. Nitta K, Iimuro S, Imai E, Matsuo S, Makino H, Akizawa T, Watanabe T, Ohashi Y, Hishida A. Risk factors for increased left ventricular hypertrophy in patients with chronic kidney disease. Clin Exp Nephrol. 2013; 17:730-742.

30. Mitsnefes MM. Cardiovascular complications of pediatric chronic kidney disease. Pediatr. Nephrol. 2008; 23:27-39.

31. Vaziri ND, Pahl MV, Crum A, Norris K. Effect of uremia on structure and function of immune system. J Ren Nutr. 2012; 22:149-156.

32. Segall L, Nistor I, Covic A. Heart failure in patients with chronic kidney disease: a systematic integrative review. Biomed Res Int. 2014; 2014:937398.
33. Martinon F, Burns K, Tschopp J. The inflammasome: a molecular platform triggering activation of inflammatory caspases and processing of proIL-beta. Mol Cell. 2002; 10:417-426.

34. Dinarello CA. Interleukin-1 beta, interleukin-18, and the interleukin-1 beta converting enzyme. Ann N Y Acad Sci. 1998; 856:1-11.

35. Dinarello CA. Immunological and inflammatory functions of the interleukin-1 family. Annu Rev Immunol. 2009; 27:519-550.

36. Parvathenani LK, Tertyshnikova S, Greco CR, Roberts SB, Robertson B, Posmantur R. P2X7 mediates superoxide production in primary microglia and is up-regulated in a transgenic mouse model of Alzheimer's disease. J Biol Chem. 2003; 278:13309-13317.

37. Thornberry NA, Bull HG, Calaycay JR, Chapman KT, Howard AD, Kostura MJ, Miller DK, Molineaux SM, Weidner JR, Aunins J. A novel heterodimeric cysteine protease is required for interleukin-1 beta processing in monocytes. Nature. 1992; 356:768-774.

38. Bergsbaken T, Cookson BT. Macrophage activation redirects yersinia-infected host cell death from apoptosis to caspase-1dependent pyroptosis. PLoS Pathog. 2007; 3:e161.

39. Dinarello CA. The IL-1 family and inflammatory diseases. Clin Exp Rheumatol. 2002; 20:S1-S13.

40. Dinarello CA. Interleukin-18 and the pathogenesis of inflammatory diseases. Semin. Nephrol. 2007; 27:98-114.

41. Turner CM, Arulkumaran N, Singer M, Unwin RJ, Tam FW. Is the inflammasome a potential therapeutic target in renal disease? BMC Nephrol. 2014; 15:21.

42. Chang A, Ko K, Clark MR. The emerging role of the inflammasome in kidney diseases. Curr Opin Nephrol Hypertens. 2014; 23:204-210.

43. Eardley KS, Zehnder D, Quinkler M, Lepenies J, Bates RL, Savage CO, Howie AJ, Adu D, Cockwell P. The relationship between albuminuria, MCP-1/CCL2, and interstitial macrophages in chronic kidney disease. Kidney Int. 2006; 69:1189-1197.

44. Anders HJ, Muruve DA. The inflammasomes in kidney disease. J Am Soc Nephrol. 2011; 22:1007-1018.

45. Lin CY, Hsu YJ, Hsu SC, Chen Y, Lee HS, Lin SH, Huang SM, Tsai CS, Shih CC. CB1 cannabinoid receptor antagonist attenuates left ventricular hypertrophy and Aktmediated cardiac fibrosis in experimental uremia. J Mol Cell Cardiol. 2015; 85:249-261.

46. Lin CY, Hsu SC, Lee HS, Lin SH, Tsai CS, Huang SM, Shih CC, Hsu YJ. Enhanced expression of glucose transporter-1 in vascular smooth muscle cells via the Akt/ tuberous sclerosis complex subunit 2 (TSC2)/mammalian target of rapamycin (mTOR)/ribosomal S6 protein kinase (S6K) pathway in experimental renal failure. J Vasc Surg. 2013; 57:475-485.

47. Mezzaroma E, Toldo S, Farkas D, Seropian IM, Van Tassell BW, Salloum FN, Kannan HR, Menna AC, 
Voelkel NF, Abbate A. The inflammasome promotes adverse cardiac remodeling following acute myocardial infarction in the mouse. Proc Natl Acad Sci U S A. 2011; 108:19725-19730.

48. Kawaguchi M, Takahashi M, Hata T, Kashima Y, Usui F, Morimoto $\mathrm{H}$, Izawa $\mathrm{A}$, Takahashi $\mathrm{Y}$, Masumoto J, Koyama J, Hongo M, Noda T, Nakayama J, et al. Inflammasome activation of cardiac fibroblasts is essential for myocardial ischemia/reperfusion injury. Circulation. 2011; 123:594-604.

49. Sandanger O, Ranheim T, Vinge LE, Bliksoen M, Alfsnes K, Finsen AV, Dahl CP, Askevold ET, Florholmen G, Christensen G, Fitzgerald KA, Lien E, Valen G, et al. The NLRP3 inflammasome is up-regulated in cardiac fibroblasts and mediates myocardial ischaemia-reperfusion injury. Cardiovasc Res. 2013; 99:164-174.

50. Toldo S, Marchetti C, Mauro AG, Chojnacki J, Mezzaroma E, Carbone S, Zhang S, Van Tassell B, Salloum FN, Abbate A. Inhibition of the NLRP3 inflammasome limits the inflammatory injury following myocardial ischemiareperfusion in the mouse. Int J Cardiol. 2016; 209:215-220.

51. Hunkerler Z, Koken T, Koca B, Kahraman A. Role of uremic toxins on apoptosis with varying periods of hemodialysis. Ther Apher Dial. 2017; 21:38-42.
52. D'Intini V, Bordoni V, Fortunato A, Galloni E, Carta M, Galli F, Bolgan I, Inguaggiato P, Poulin S, Bonello M, Tetta C, Levin N, Ronco C. Longitudinal study of apoptosis in chronic uremic patients. Semin Dial. 2003; 16:467-473.

53. Muteliefu G, Enomoto A, Niwa T. Indoxyl sulfate promotes proliferation of human aortic smooth muscle cells by inducing oxidative stress. J Ren Nutr. 2009; 19:29-32.

54. Himmelfarb J, Stenvinkel P, Ikizler TA, Hakim RM. The elephant in uremia: oxidant stress as a unifying concept of cardiovascular disease in uremia. Kidney Int. 2002; 62:1524-1538.

55. Kotur-Stevuljevic J, Simic-Ogrizovic S, Dopsaj V, Stefanovic A, Vujovic A, Ivanic-Corlomanovic T, Spasic S, Kalimanovska-Spasojevic V, Jelic-Ivanovic Z. A hazardous link between malnutrition, inflammation and oxidative stress in renal patients. Clin Biochem. 2012; 45:1202-1205.

56. Yang HC, Zuo Y, Fogo AB. Models of chronic kidney disease. Drug Discov Today Dis Models. 2010; 7:13-19.

57. Kennedy DJ, Elkareh J, Shidyak A, Shapiro AP, Smaili S, Mutgi K, Gupta S, Tian J, Morgan E, Khouri S, Cooper CJ, Periyasamy SM, Xie Z, et al. Partial nephrectomy as a model for uremic cardiomyopathy in the mouse. Am J Physiol Renal Physiol. 2008; 294:F450-F454. 